Virginia Commonwealth University vCU Scholars Compass

2012

\title{
Controlled synthesis of superparamagnetic iron- oxide nanoparticles by phase transformation
}

Mark A. Laurenzi

Catholic University of America

Everett E. Carpenter

Virginia Commonwealth University, ecarpenter2@vcu.edu

Follow this and additional works at: http://scholarscompass.vcu.edu/chem_pubs

Part of the Chemistry Commons

Laurenzi, M. A., and Carpenter, E. E. Controlled synthesis of superparamagnetic iron-oxide nanoparticles by phase transformation. Journal of Applied Physics, 111, 07B520 (2012). Copyright (C) 2012 American Institute of Physics.

\section{Downloaded from}

http://scholarscompass.vcu.edu/chem_pubs/37

This Article is brought to you for free and open access by the Dept. of Chemistry at VCU Scholars Compass. It has been accepted for inclusion in Chemistry Publications by an authorized administrator of VCU Scholars Compass. For more information, please contact libcompass@vcu.edu. 


\title{
Controlled synthesis of superparamagnetic iron-oxide nanoparticles by phase transformation
}

\author{
Mark A. Laurenzi III, a) and Everett E. Carpenter, ${ }^{2, b)}$ \\ ${ }^{1}$ Department of Physics, Catholic University of America, Washington, D.C. 20064, USA \\ ${ }^{2}$ Department of Chemistry, Virginia Commonwealth University, Richmond, Virginia 23284, USA
}

(Presented 1 November 2011; received 23 September 2011; accepted 9 November 2011; published online 6 March 2012)

\begin{abstract}
A synthesis procedure for generating a uniform distribution of iron-oxide nanoparticles from an amorphous precursor is reported. The investigation suggests no evidence of the formation of unwanted surface oxide layers, internal stress, and multiple phases. This is likely because the physical properties of the diffusion fields surrounding the nanoparticles are self-limiting by $\mathrm{Fe}(\mathrm{II})$ depletion. Inside the diffusion field surrounding the nucleation site, decreasing Fe(II) concentration results in a decrease in the diffusion rate that continues to decrease until self-limiting kinetic arrest occurs. The initial $\mathrm{Fe}$ (II) concentration is established by reducing a system abundant in $\mathrm{Fe}$ (III) by means of exposure to $\mathrm{CO} / \mathrm{CO}_{2}$ gas at high temperature. (c) 2012 American Institute of Physics. [doi:10.1063/1.3676232]
\end{abstract}

\section{INTRODUCTION}

It is of both practical and theoretical interest to develop a controlled synthesis procedure for producing single-domain, single-phase iron-oxide nanoparticles with a uniform distribution in average dimension in the range of 2-30 nm. ${ }^{1}$ Several synthesis procedures, such as polyol process, ${ }^{2}$ mechanochemical reaction, ${ }^{3}$ and bacterial iron reduction ${ }^{1}$ were investigated in the last decade. In spite of this, each of the previous is subject to undesirable synthesis artifacts namely, surface oxide layers, internal stress, and non-uniform phase. This work investigates synthesis by phase transformation or rather, devitrification $^{4-7}$ that seeks to overcome the formation of undesirable artifacts, and thus, may provide investigators with a less obstructed view for investigating finite size effects.

As the number of atoms on the surface of the material becomes comparable to those in the volume, new physical characteristics emerge. For example: the Verwey transition in a system where the surface area to volume ratio is less than 1 exhibits a transition temperature $\mathrm{T}_{\mathrm{v}} \sim 120-125 \mathrm{~K}$ whereas, Poddar et al. has shown that $\mathrm{T}_{\mathrm{v}}$ is shifted to $96 \mathrm{~K}$ for a system of nanoparticles where the surface area to volume ratio is approximately unity or greater. ${ }^{8}$ Nature's achievement of a local minima state of free energy can be evidenced by predictable physical characteristics.

The synthesis procedure presented in this work overcomes the shortcomings attributable to stress induced by mechanical sizing, because the nanoparticles develop within an adaptable, supporting amorphous matrix. Excess oxygen needed to form surface oxides and/or multiple phases that occur in a reducing atmosphere is restrained, since transformation takes place within the volume of a host matrix. A diffusion field, within the host matrix, surrounds the nucleation site and its viscosity increases as the concentration of $\mathrm{Fe}(\mathrm{II})$

\footnotetext{
a)Electronic mail: Mark.laurenzi@gmail.com.

b)Electronic mail: Ecarpenter2@vcu.edu.
}

decreases and hence, provides a mechanism for the nucleation and growth of uniform distribution of nanoparticles.

Woltz et al. studied a system similar to that of this work where the method of synthesis is considerably different and produces nanoparticles of mixed phase composition. ${ }^{5}$ Another relevant work claims a single phase. ${ }^{6}$ Unlike the previous work, the initial $\mathrm{Fe}$ (II) concentration is selected by high temperature reduction and used to control the resultant average dimension of the transforming phase.

\section{EXPERIMENTAL}

The NCFB system is composed of $\left(4.9 \% \mathrm{Na}_{2} \mathrm{O}\right)-(33.3 \%$ $\mathrm{CaO})-\left(17.1 \% \mathrm{Fe}_{2} \mathrm{O}_{3}\right)-\left(44.7 \% \mathrm{~B}_{2} \mathrm{O}_{3}\right.$ (by mol). Reagent grade chemicals were mixed in $200 \mathrm{~g}$ batches then fired in a platinum crucible at $1200{ }^{\circ} \mathrm{C}$. A platinum tube, down line from a calibrated gas proportioner, was situated just above the bottom of the crucible so as to allow the $\mathrm{CO} / \mathrm{CO}_{2}$ gas to interact with the system. A cover with a hole was placed on the crucible to control the atmosphere directly above the system. The system is homogenized for $1.5 \mathrm{~h}$ at $1200{ }^{\circ} \mathrm{C}$ then reduced in situ. The reduction time was determined experimentally by observing the relative maximum oxidation state available for a fixed $\mathrm{CO} / \mathrm{CO}_{2}$ ratio. Three samples NCFB1, NCFB2, and $\mathrm{NCFB} 3$ are generated by selecting $\mathrm{CO} / \mathrm{CO}_{2}$ ratios of 1,3 , and 4, respectively, and listed in Table I. The exposure time should be minimized because boron is volatile under high temperature conditions and its concentration within the NCFB system is observed to decrease with increasing exposure duration. With decreasing boron concentration the viscosity is observed to increase and therefore, the diffusion field surrounding a nucleation site is strongly affected. After reduction, the system is quenched between two 6 in. diameter and $\frac{1}{2}$ in. thick copper plates. It is important to quench the system fast enough such that the liquid state is locked in and crystallization does not occur. This is because the Fe(II) oxidation state is estimated by Mossbauer spectroscopy and 
TABLE I. Fe(II) oxidation state $\Sigma$.

\begin{tabular}{lcc}
\hline \hline & $\sum_{\text {Plate }}$ & $\sum_{\text {Roller }}$ \\
\hline NCFB 1 & $13.4 \%$ & $10.2 \%$ \\
NCFB 2 & $33.2 \%$ & $20.2 \%$ \\
NCFB 3 & $53.8 \%$ & $42.4 \%$ \\
\hline \hline
\end{tabular}

crystallization would obfuscate important features of the spectra. $10 \mathrm{~g}$ samples were placed into a small platinum crucible, the chamber flooded with a conventional grade of $\mathrm{N}_{2}$ to restrain the conversion of $\mathrm{Fe}$ (II) to $\mathrm{Fe}(\mathrm{III})$ that is favored by the system at high temperature. After reaching $1200{ }^{\circ} \mathrm{C}$, the system was quenched by copper rollers. The surface speed and gap of the rollers was set to $0.83 \mathrm{~m} / \mathrm{s}$ and $\sim 100 \mu \mathrm{m}$, respectively.

The oxidation state $\Sigma$ provides information about the concentration of iron for the NCFB system in the amorphous state and is given by the following equation:

$$
\Sigma=\left\{\frac{C_{F e(I I)}}{C_{F e(I I)}+C_{F e(I I I)}}\right\} \cdot 100,
$$

where $C_{F e(I I)}$ and $C_{F e(I I I)}$ are the concentration of the $\mathrm{Fe}(\mathrm{II})$ and $\mathrm{Fe}$ (III) ions present in the initial amorphous NCFB system. $\Sigma$ is estimated through Mossbauer spectroscopy by fitting the $\mathrm{Fe}(\mathrm{II})$ and $\mathrm{Fe}(\mathrm{III})$ sextets that correspond to the respective concentrations of iron in the amorphous precursor. Table I shows that the nitrogen atmosphere was unable to fully suppress re-oxidation. The initial Fe(II) oxidation state before annealing is given by $\Sigma_{\text {Roller }}$. Subsequently, chips were collected and ground to particles in the range $0<x<140 \mu \mathrm{m}$, then annealed at $500-600{ }^{\circ} \mathrm{C}$ for several hours.

The physical state, crystalline structure, and the average dimension and phase distribution was determined at room temperature by a Thermo X'tra Powder diffractometer with a $\mathrm{Cu}$ X-ray tube source. The diffractometer is calibrated with respect to $2 \theta$ using a quartz standard under $45 \mathrm{kV}$ and $40 \mathrm{~mA}$ conditions. The accuracy of the calibration is approximately $2 \theta \approx 0.02^{\circ}$. Fe(II) oxidation state was estimated by Mossbauer spectroscopy (MS) 1200 Spectrometer. The velocity scale of the spectrometer is calibrated by comparison of the Mossbauer absorption lines of an $\alpha$-iron standard reference in transmission geometry. Additionally, the average dimension as well as shape was estimated and observed, respectively, by transmission electron microscopy (TEM). The TEM images were collected using a JEOL 2100 operating at $200 \mathrm{kV}$. The magnetic state of the system was investigated by the superconducting quantum interference device (SQUID). The SQUID was calibrated with $\mathrm{HgCo}(\mathrm{CNS})_{4}$ at room temperature with a value of $16.44 \cdot 10^{-6} \mathrm{emu} / \mathrm{g}$. The sample holder consists of a \#2 gel cap and a standard straw. The DC susceptibility of the sample holder was measured from $\mathrm{T}=2-350 \mathrm{~K}$ and $\mathrm{a}$ point to point background subtraction performed along with subtraction of the diamagnetic contribution.

\section{RESULTS AND DISCUSSION}

The diffraction patterns in Figs. 1(a)-1(c) show a broad diffuse amorphous feature indicative of the absence of crys-

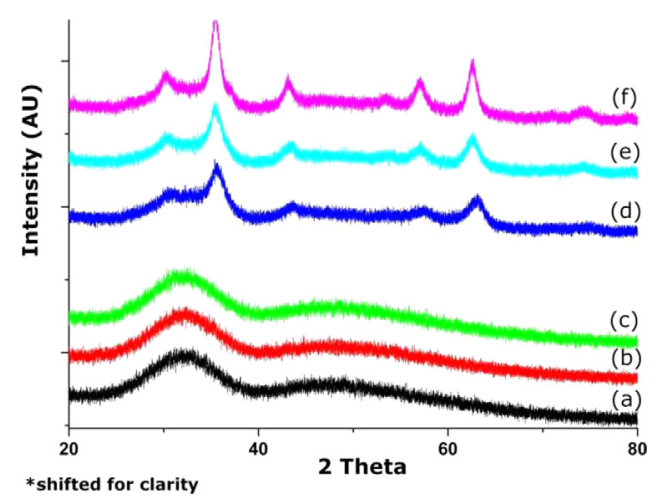

FIG. 1. (Color online) Amorphous XRD patterns for NCFB1, NCFB2, and NCFB3 are shown in (a)-(c) (after roller quenching), (d)-(f) for NCFB1, NCFB2, and NCFB 3, respectively, show broadened diffraction features (after annealing).

talline structure that issues in part, from the distribution of bonding angles of the NCFB system. Figures 1(d)-1(f) show clear presence of nano-crystalline features. Distinguishing features of other phases of iron-oxide are not present in Figs. 1(d)-1(f). However, it is virtually impossible to distinguish maghemite from magnetite by XRD. In spite of this, the features present correspond best to magnetite, for this reason within the limits of error, the features shown are those of magnetite. $6,9,10$ The diffraction feature located within the range $59^{\circ} \leq 2 \theta \leq 66^{\circ}$ corresponds to the (440) diffraction plane of magnetite. ${ }^{10}$ The features of this diffraction plane in combination with the Stokes-Wilson equation (WSE) allowed for estimation of the average dimension. ${ }^{11}$

Diffraction peak broadening is represented by the integral breadth $\beta$, wavelength of the impinging $\mathrm{x}$-ray $\lambda$ and impinging $\mathrm{x}$-ray angle $\theta$ are related to the average dimension of the nano-crystalline structure by the WSE,

$$
\langle L\rangle_{v o l}=\frac{\lambda}{\beta \cdot \cos \theta} .
$$

The contribution to the broadened feature from remaining matrix was removed by linear subtraction and the integral breadth was corrected for instrumental broadening. The area under the feature is estimated by Pearson VII function fit. In order to investigate the presence of strain in the system the Williamson-Hall (WH) strain analysis was applied. ${ }^{12}$ The WH strain analysis indicates that any strain present is negligible. The average dimension $\langle L\rangle_{v o l}$ of NCFB1-3 is reported in Table II.

The average dimension estimated by TEM of NCFB1-3 is reported in Table II. The shape observed is approximately spherical as shown in Fig. 2. The lattice parameters for magnetite and maghemite are different. If multiple phases were

TABLE II. Estimated Ave. dimension.

\begin{tabular}{lcc}
\hline \hline & $\langle\mathrm{L}\rangle_{\text {vol }}$ & $\langle\mathrm{D}\rangle_{\text {area }}$ \\
\hline NCFB 1 & $2.86 \mathrm{~nm}$ & $5.11 \mathrm{~nm}$ \\
NCFB 2 & $2.94 \mathrm{~nm}$ & $4.51 \mathrm{~nm}$ \\
NCFB 3 & $4.41 \mathrm{~nm}$ & $4.86 \mathrm{~nm}$ \\
\hline \hline
\end{tabular}




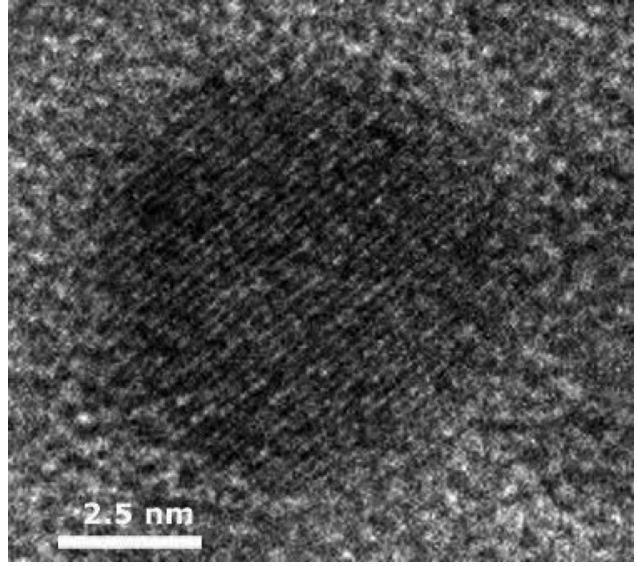

FIG. 2. TEM image of NCFB3 illustrating an approximately spherical ironoxide nanoparticle.

present, then a noticeable change in fringe spacing would be present. No noticeable change in spacing is observed, for this reason within the limits of error, no evidence of multiple phases is found. Furthermore, such a close comparison between an estimate of the volume weighted sort $\langle L\rangle_{v o l}$ and the area weighted sort $\langle D\rangle_{\text {Area }}$ suggests that the nanocrystalline structure are single-domain. It was observed that the glass transition temperature $\mathrm{T}_{\mathrm{g}}$ is strongly affected by $C_{F e(I I)}$ and weakly affected by $C_{F e(I I I)} \cdot \mathrm{T}_{\mathrm{g}}$ decreases with increasing $C_{F e(I I)}$ and increases with decreasing $C_{F e(I I)}$. It was also observed that transformation for short annealing time is rapid, whereas annealing for long times results in negligible change, if any, in average dimension. This selflimiting phenomenon is a consequence of $C_{F e(I I)}$.

Superparamagnetic nano-crystalline systems display zero hysteresis under an external magnetic field and fail to saturate magnetically even in high external magnetic fields above the blocking temperature. ${ }^{13}$ The FDM data acquired for all systems at $300 \mathrm{~K}$ display zero $\mathrm{M}_{\mathrm{R}}$ and $\mathrm{H}_{\mathrm{C}}$. This indicates that a major fraction of the nanoparticles are unblocked at $300 \mathrm{~K}$. In Fig. 3, the FDM acquired at $10 \mathrm{~K}$ show non-zero values for $\mathrm{M}_{\mathrm{R}}$ and $\mathrm{H}_{\mathrm{C}}$, Table III. At $10 \mathrm{~K}$ the system shows

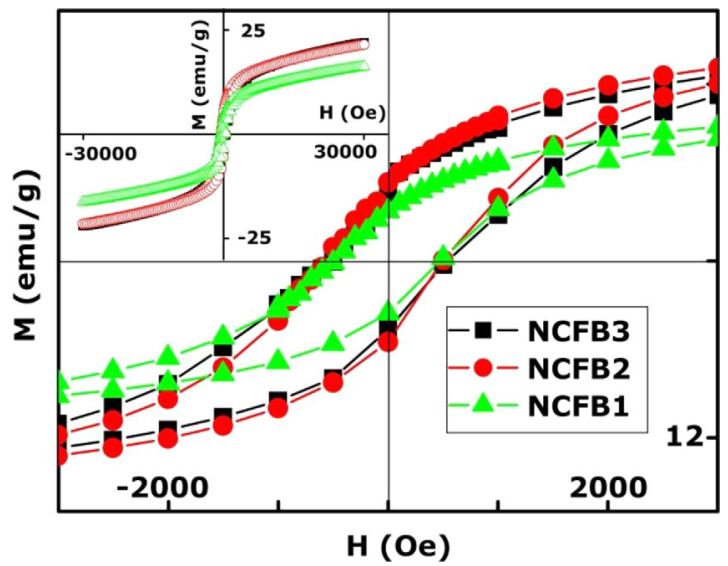

FIG. 3. (Color online) FDM curves show that the NCFB systems are blocked at $10 \mathrm{~K}$.
TABLE III. NCFB1-3 $10 \mathrm{~K}$ (data from Fig. 3).

\begin{tabular}{lcc}
\hline \hline & Rem. Mag. $\mathrm{M}_{\mathrm{R}}$ & ${\text { Coercivity } \mathrm{H}_{\mathrm{c}}}$ \\
\hline NCFB 1 & $3.39(\mathrm{emu} / \mathrm{g})$ & $474(\mathrm{Oe})$ \\
NCFB 2 & $4.57(\mathrm{emu} / \mathrm{g})$ & $494(\mathrm{Oe})$ \\
NCFB 3 & $5.35(\mathrm{emu} / \mathrm{g})$ & $538(\mathrm{Oe})$ \\
\hline \hline
\end{tabular}

that $\mathrm{H}_{\mathrm{C}}$ increases with increasing dimension. The slight increase in $\mathrm{H}_{\mathrm{C}}$ suggests that the volume retains a magnetic contribution in spite of the increasing number of atoms participating on the surface. The estimated number of atoms participating on the surface of a magnetite particle with an average diameter of 5, 4, and $3 \mathrm{~nm}$ ranges from $25 \%, 32 \%$, and $42 \%$ of the total atoms of the particle, respectively. The systems in their failure to reach saturation magnetization possibly reflects the presence of a demagnetizing nonmagnetic layer at the surface of the nanoparticle comprising a considerable percentage of atoms that makeup the nanoparticle and spin canting. ${ }^{14}$

\section{CONCLUSION}

Iron-oxide nanoparticles nucleate and grow within an amorphous host matrix where the final average dimension of the evolving crystalline phase is controlled by a self-limiting diffusion field. As the concentration of Fe(II) is depleted, the glass transition temperature increases so as to approach the experimental annealing temperature and results in selflimiting kinetic seizure. The fine control of size as shown with increasing $\mathrm{Fe}(\mathrm{II})$ concentration as explained by the selflimiting effect is promising for providing investigators with iron-oxide nanoparticles.

${ }^{1}$ C. Zhang, H. Vali, Christopher S. Romanek, T. J. Phelps, and S. V. Liu, American Mineralogist, December 1998, 83, 1409-1418.

${ }^{2}$ Zachary J. Huba, Kyler J. Carroll, and Everett Carpenter, J. Appl. Phys. 109, 07B514 (2011).

${ }^{3}$ Chun-Rong Lin, Yuan Ming Chu, and Sheng-Chang Wang, J. Mater. Sci. Lett. 60, 447 (2006).

${ }^{4}$ Miyuki Hayashi, Masahiro Susa, and Kazuhiro Nagata, J. Appl. Phys. 85, 2257 (1999).

${ }^{5}$ Sebastian Woltz and Christian Russel, J. Non-Cryst. Solids 337, 226 (2004).

${ }^{6}$ S. Woltz, R. Hiergeist, P. Gornert, and C. Russel, J. Magn. Magn. Mater. 298, 7 (2006).

${ }^{7}$ Paolo Allia, Oana Bretcanu, Enrica Verne, Rederica Celegato, Marco Coisson, Paola Tiberto, Franco Vinai, Federico Spizzo, and Melissa Tamisari, J. Appl. Phys. 105, 083911-1 (2009).

${ }^{8}$ P. Poddar, T. Fried, and G. Markovich, Phys. Rev. B 65, 172405 (2002).

${ }^{9}$ R. M. Cornell and U. Schwertmann, The Iron Oxides, 2nd ed. (WileyVCH, New York, 1996).

${ }^{10}$ T. Belin, N. Guigue-Millot, T. Caillot, D. Aymes, and J. C. Niepce, J. Solid State Chem. 163, 459 (2002).

${ }^{11} \mathrm{H}$. Klug and L. Alexander, X-Ray Diffraction Procedures for Polycrystalline and Amorphous Materials, 2nd ed., Ch. 9 (John Wiley and Sons, New York, 1974).

${ }^{12}$ M. M. Hall, V. G. Veeraraghavan, H. Rubin, and P. G. Winchell, J. Appl. Crystallogr. 10, 66 (1977)

${ }^{13}$ G. Kataby, Y. Koltypin, A. Ulman, I. Felner, and A. Gedanken, Appl. Surf. Sci. 201, 191 (2002).

${ }^{14}$ R. N. Panda, N. S. Gajbhiye, and G. Balaji, J. Alloys Compd. 326, 50 (2001). 